\title{
Extended Fronto-Orbital
}

\section{Approaches to the Anterior Cranial Base: Variations on a Theme}

\begin{abstract}
Combined frontal, orbital and zygomatic osteotomies have expanded the skull base surgeon's repertoire of approaches to the anterior skull base. Techniques borrowed from craniofacial surgery provide for extensive exposure of the orbit and anterior fossa while minimizing brain retraction. This article emphasizes the variations on the theme of frontoorbital craniotomy that allow this approach to be adapted to the precise location and extent of the lesion to be excised. Familiarity with these versatile techniques is an important part of the skull base surgeon's armamentarium. (Skull Base Surgery, Volume 2, Number 3, 1992, p. 134)
\end{abstract}

Advances in craniofacial and cranial base surgery have vastly improved our ability to approach the anterior skull base and orbit for the treatment of benign and malignant lesions. The melding of techniques developed in different disciplines now allows the more or less routine resection of lesions that cross what used to be anatomic and disciplinary boundaries. Craniofacial approaches to the anterior skull base and orbit can be tailored in various ways to allow optimal exposure of the lesion in question without unnecessarily expanding or complicating the procedure. It is these variations on the standard fronto-orbital approach to the anterolateral skull base that we wish to emphasize.

\section{FRONTO-ORBITAL CRANIOTOMY}

Although first proposed early in the 20th century by Frazier ${ }^{1}$ and McArthur, ${ }^{2}$ the standard fronto-orbital craniotomy was popularized and standardized by Jane and associates. ${ }^{3}$ The frontal craniotomy is extended to include the orbital roof and zygomatic process of the frontal bone down to the frontozygomatic suture. Although Jane's de- scription of the operation includes cutting the orbital roof with a Gigli saw, Maroon and Kennerdell ${ }^{4}$ have pointed out that the normal orbital roof is sufficiently thin and it will fracture leaving a substantial portion of the orbital roof attached to the craniotomy flap. Figure 1 shows the standard fronto-orbital craniotomy in outline form. Case 1 presents an example of its use.

\section{Case 1}

A 35-year-old man noted progressive decline in visual acuity in the left eye to $20 / 200$. He had no other complaints or significant medical illnesses. His neurologic examination was normal with the exception of left eye visual field, shown in Figure 2A. The magnetic resonance image shown in Figure 3 documents a lesion in the medial orbital apex distorting the optic nerve. This lesion was approached through the standard fronto-orbital craniotomy jointly by the neurologic and ophthalmologic surgeon. A gross total excision of the lesion, which was a cavernous hemangioma of the dura, was accomplished. Postoperatively visual acuity improved to $20 / 100$. The visual field was expanded as shown in Figure 2B. 


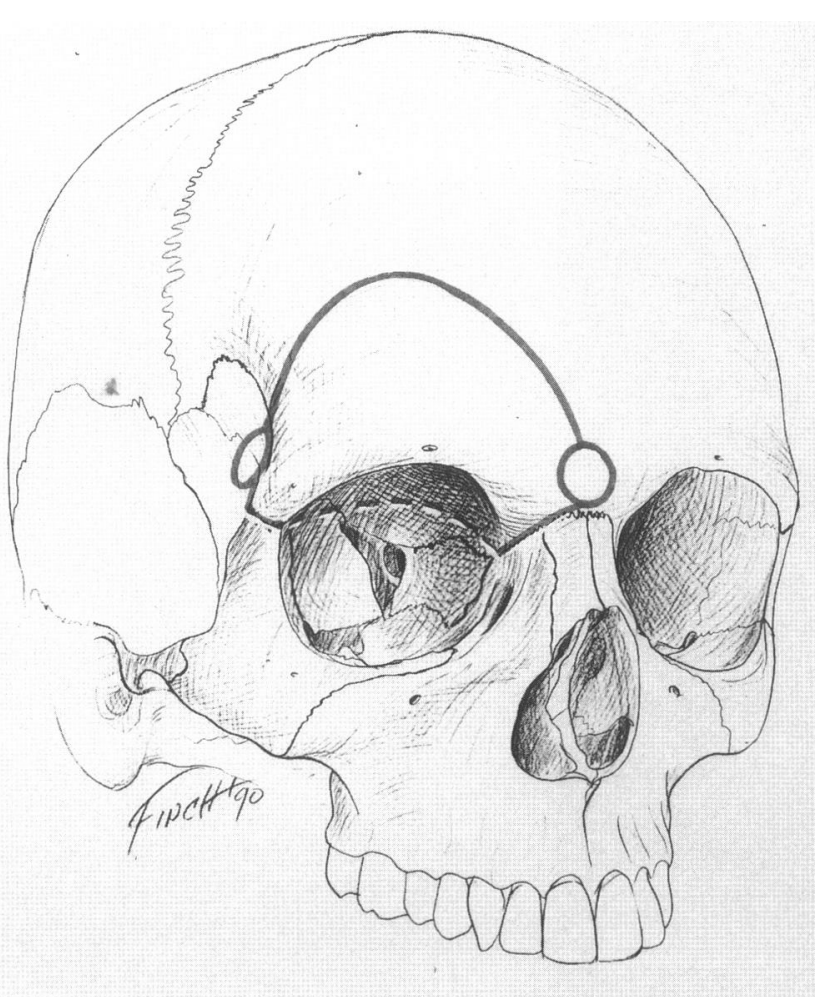

Figure 1. Artist's rendition of the standard frontoorbital craniotomy.

\section{LATERAL ORBITAL EXTENSION}

When greater access to the lateral orbital wall and orbital floor is required, the lateral osteotomy can be carried out at the level of the zygomatic arch, rather than the frontozygomatic suture (Fig. 4). If the lateral orbital rim is left intact, the lateral orbital wall can be removed without creating significant cosmetic deformity or functional impairment. This extension of exposure has been proposed by Al-Mefty and Fox ${ }^{5}$ as a two-piece crani- otomy. We have found is quite feasible to carry it out as a one-piece flap. Case 2 presents an example of such a procedure.

\section{Case 2}

This 44-year-old man presented with a recurrent intraosseous meningioma of the right frontal bone. Figure 5A demonstrates the extent of bone involvement on a threedimensional computed tomography reconstruction. Osteotomies were made through the superior orbital rim and through the inferior lateral orbital rim at the junction with the zygomatic arch. Reconstruction was achieved with contour-matched outer table calvarial bone grafts. Figure $5 \mathrm{~B}$ shows the postoperative result.

\section{ZYGOMATIC EXTENSION}

When more complete exposure of the lateral and inferior orbit, as well as the middle cranial fossa, is required, essentially the entire zygoma can be removed along with the frontal craniotomy. When extensive exposure of the anterior and middle cranial fossae is required, the exposure that has been popularized as the orbitozygomatic craniotomy by Sekhar et $\mathrm{al}^{6}$ and many others, nicely summarized by McDermott et al, ${ }^{7}$ can be used. For such applications the procedure is best performed as a two-part craniotomy, the first being a standard frontotemporal craniotomy followed by an orbitozygomatic osteotomy. This is shown in Figure 6A. After the frontotemporal craniotomy is carried out, an osteotomy is made from the most anterior part of the craniotomy into the orbital roof. With the periobita protected below and the dura retracted above, osteotomies are made across the orbital roof to the burr hole, which is placed behind the zygomatic process of the frontal bone in such a fashion as to enter both orbit and anterior fossa. The orbital osteotomy may be adjusted anteriorly or posteriorly, depending on the amount of
Figure 2. Preoperative (left) and postoperative (right) visual fields for the left eye of the patient reported in case 1.
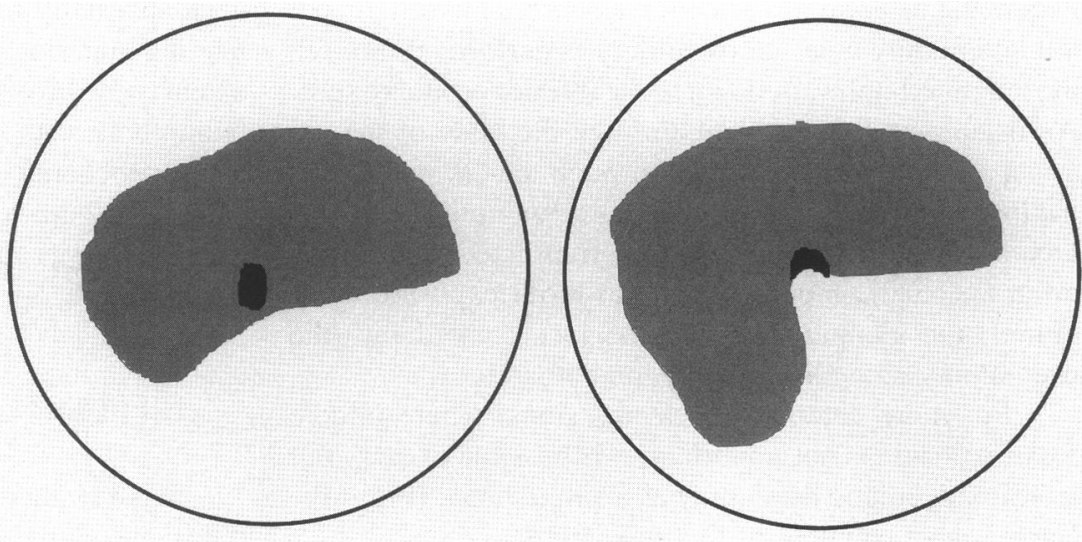
A

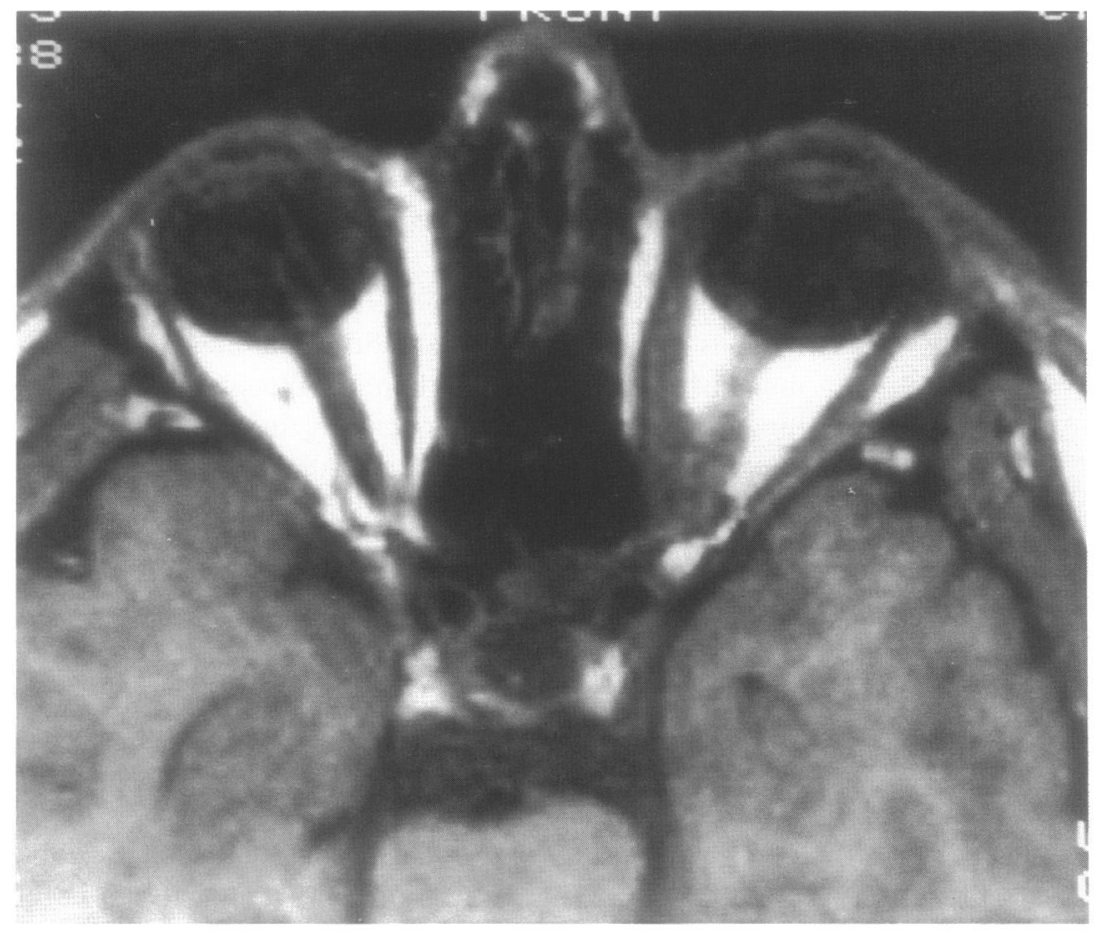

B

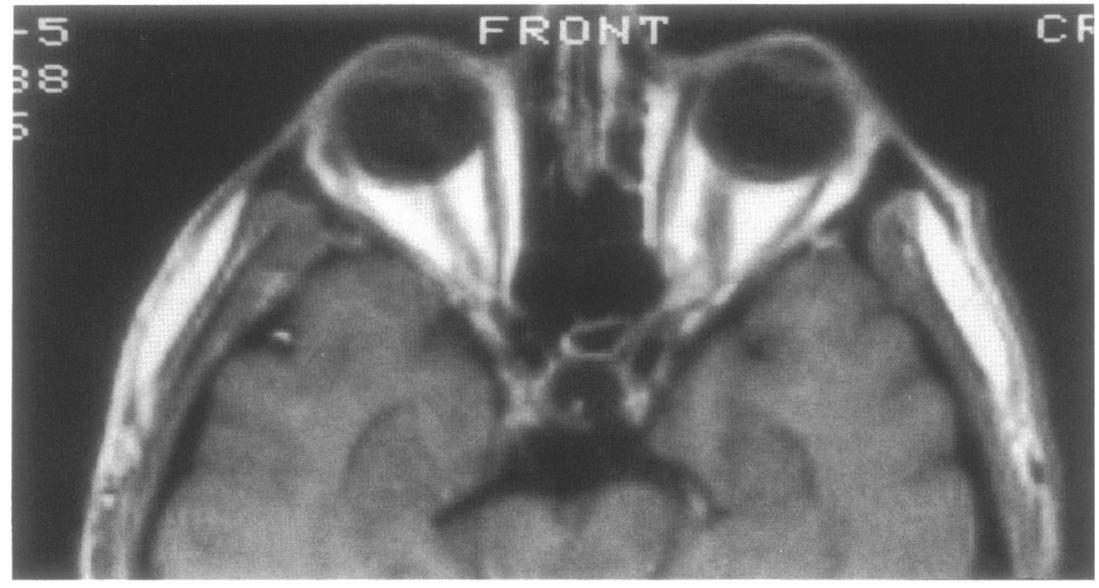

Figure 3. Preoperative $(A)$ and postoperative (B) magnetic resonance imaging from case 1 . orbital exposure required. If at least two thirds of the orbital roof is retained with flap, pulsating exophthalmos should be a rare postoperative phenomenon. The key to the zygomatic osteotomies is the inferior orbital fissure. From the lateral burr hole, an osteotomy is performed through the lateral orbital wall, down to the inferior orbital fissure. An osteotomy is then made through the body of the zygoma anteriorly and extended through the orbital floor to the inferior orbital fissure. The only remaining bone is the arch of the zygoma, which is then transected, freeing the orbitozygomatic block. If very posterior exposure is required, the glenoid fossa can be incorporated into the osoteotomy along with the zygomatic arch.

For more anteriorly located lesions, where middle fossa exposure is not important, it is possible to carry out a orbitozygomatic osteotomy as a single block (Fig. 6B).

\section{Case 3}

This $2 \frac{1}{2}$-year-old boy had a lymphangioma of the neck subtotally resected at age 6 weeks. It recurred, extending superiorly through the inferior orbital fissure to extensively involve the orbit (Fig. 7). A fronto-orbital craniotomy with zygomatic extension was performed to expose the orbit extensively and a substantial subtotal removal of the lesion was accomplished. A significant reduction in proptosis and improvement in appearance resulted.

\section{BIFRONTO-ORBITAL CRANIOTOMY}

It is a straightforward extension of any of these procedures to extend the frontal craniotomy to the opposite side 


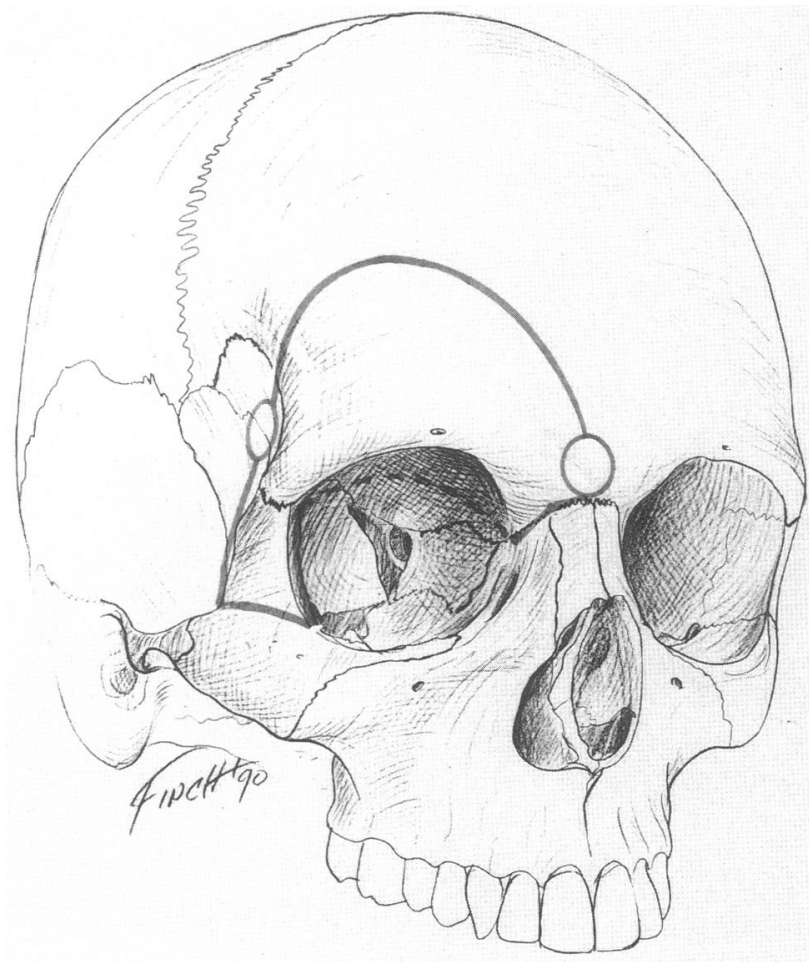

Figure 4. Artist's rendition of the lateral orbital extension of the fronto-orbital craniotomy.
(Fig. 8). This allows extensive access to the entire anterior cranial fossa, while giving additional access to the orbit on one side. Case 4 is an illustration.

\section{Case 4}

This 47-year-old man was initially diagnosed as having an inverting papilloma of the nasopharynx. After four operations and radiation therapy, squamous cell carcinoma of the sphenoid sinus was diagnosed (Fig. 9). The lesion extended to the medial orbital apex on the left side. In order to access the entire sphenoid sinus, upper clivus, and medial orbital apex, a bifrontal orbital craniotomy was utilized. A combined otolaryngologic and neurosurgical procedure and gross total excision of the tumor was accomplished. Reconstruction of the anterior fossa floor with split cranium and pericranial grafts was accomplished.

\section{BIFRONTAL-BIZYGOMATIC CRANIOTOMY}

In theory, the fronto-orbital craniotomy with zygomatic extension could be carried out bilaterally; in fact, we have used such a procedure for first-stage correction of the craniofacial associated anomaly with Crouzon's syndrome. The osteotomies are schematically shown in Figure 10 .
A

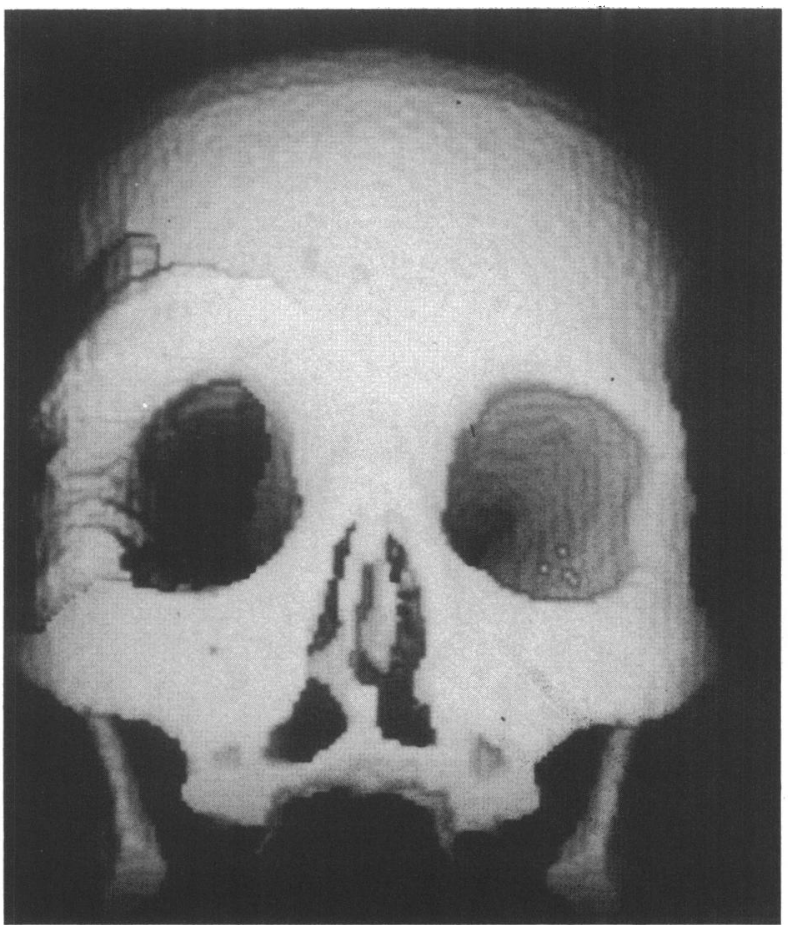

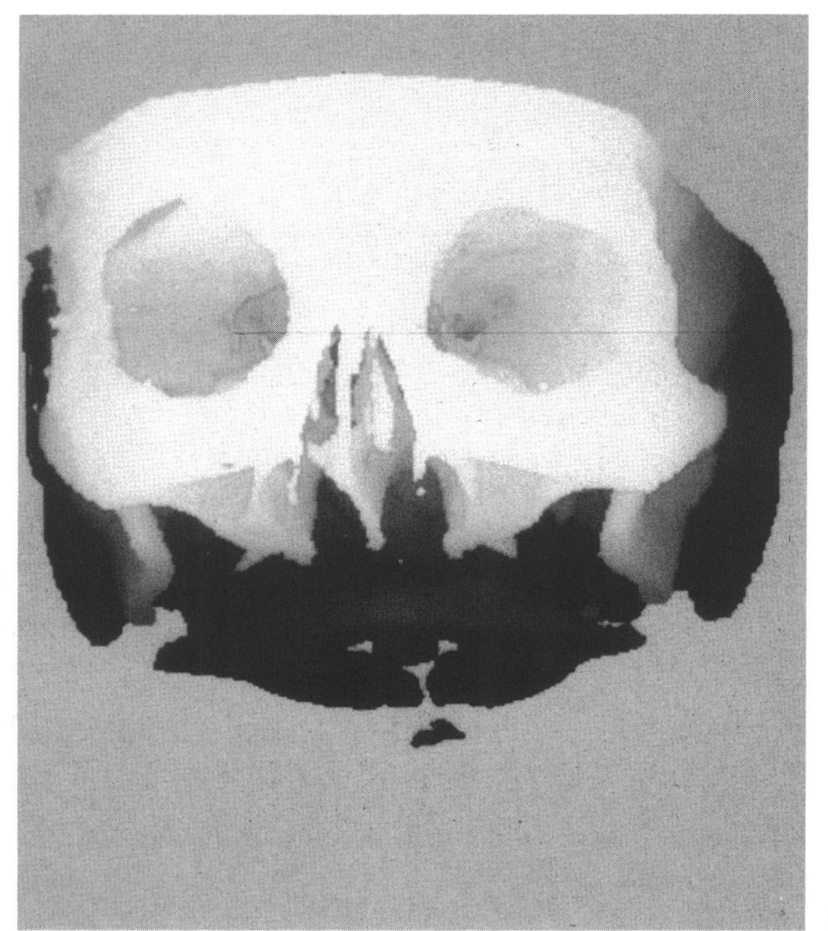

B

Figure 5. A: Three dimensional reconstructed computed tomography (CT) scan showing the extent of bony involvement of the intraosseous meningioma in case 2. B: 3D reconstructed CT showing the postoperative result after resection of the lesion and reconstruction with split cranial graft. 

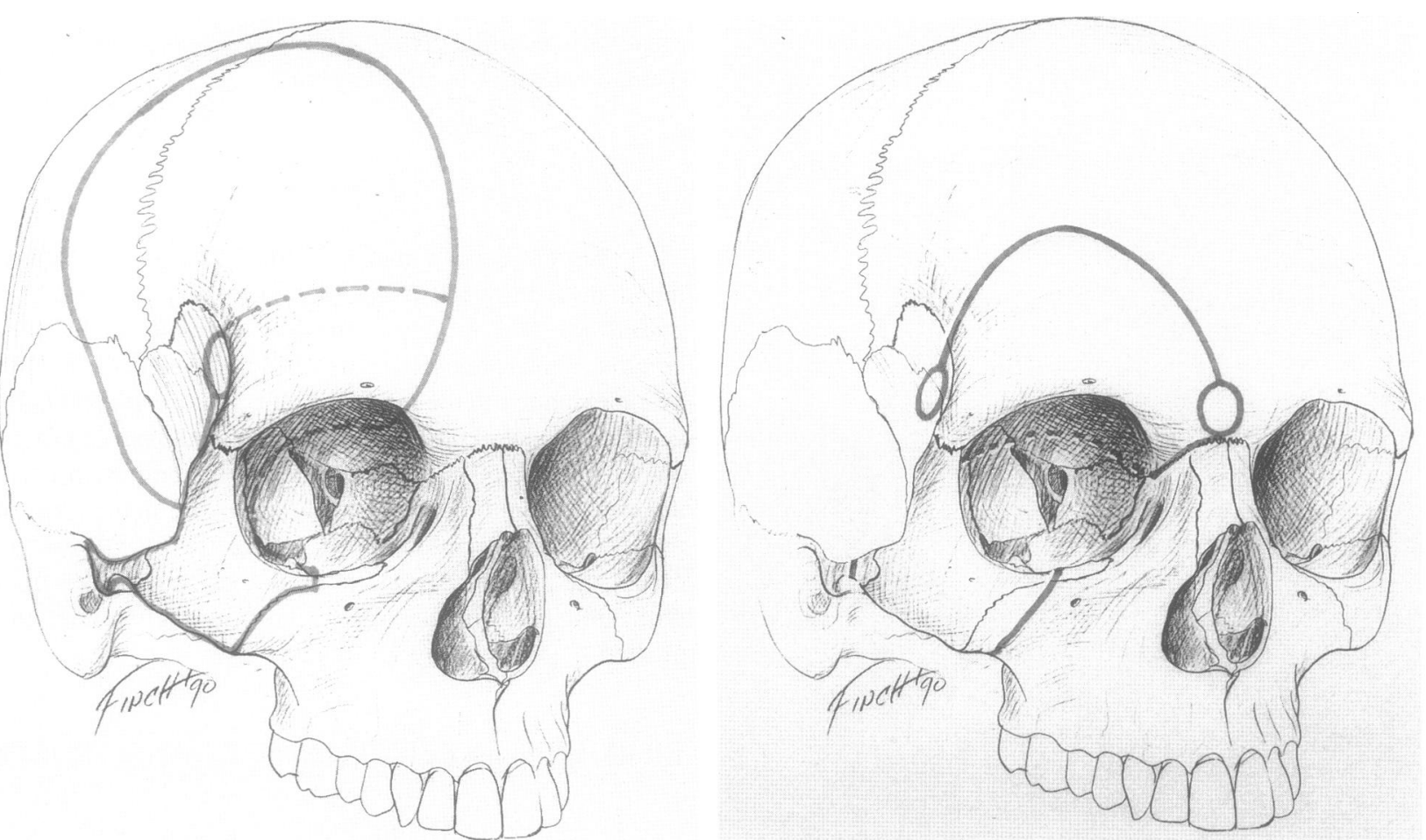

Figure 6. A: Two part frontotemporal craniotomy plus orbitozygomatic osteotomy. (Redrawn with permission from McDermott et al.6) B: Artist's rendition of the fronto-orbital craniotomy with zygomatic extension.

A

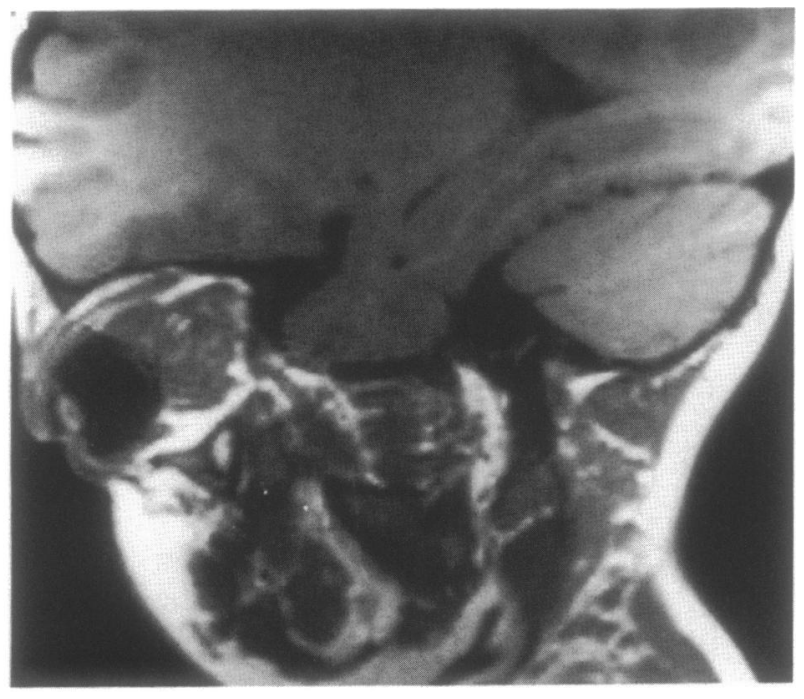

Figure 7. A: Preoperative parasagittal $\mathrm{T} 1$ weighted magnetic resonance imaging (MRI) demonstrating intraorbital lymphangioma with anteroinferior displacement of the globe. B: Preoperative $\mathrm{T}^{2}$ weighted coronal MRI on the same patient. (Figure continued on next page)

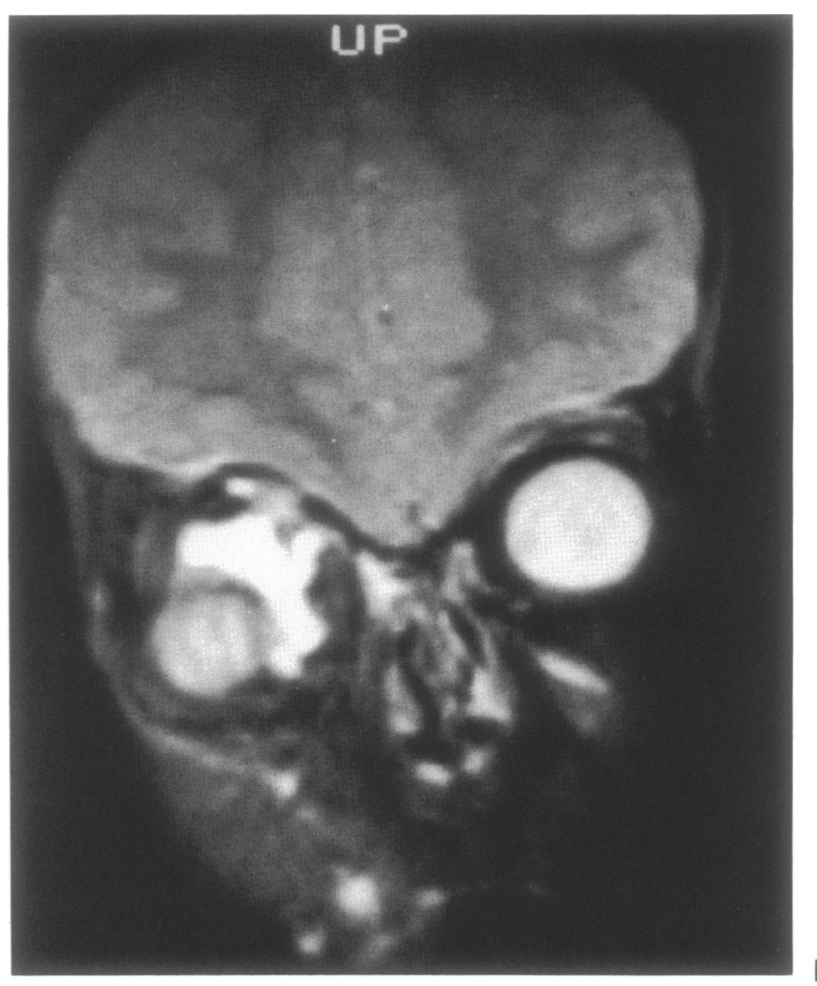



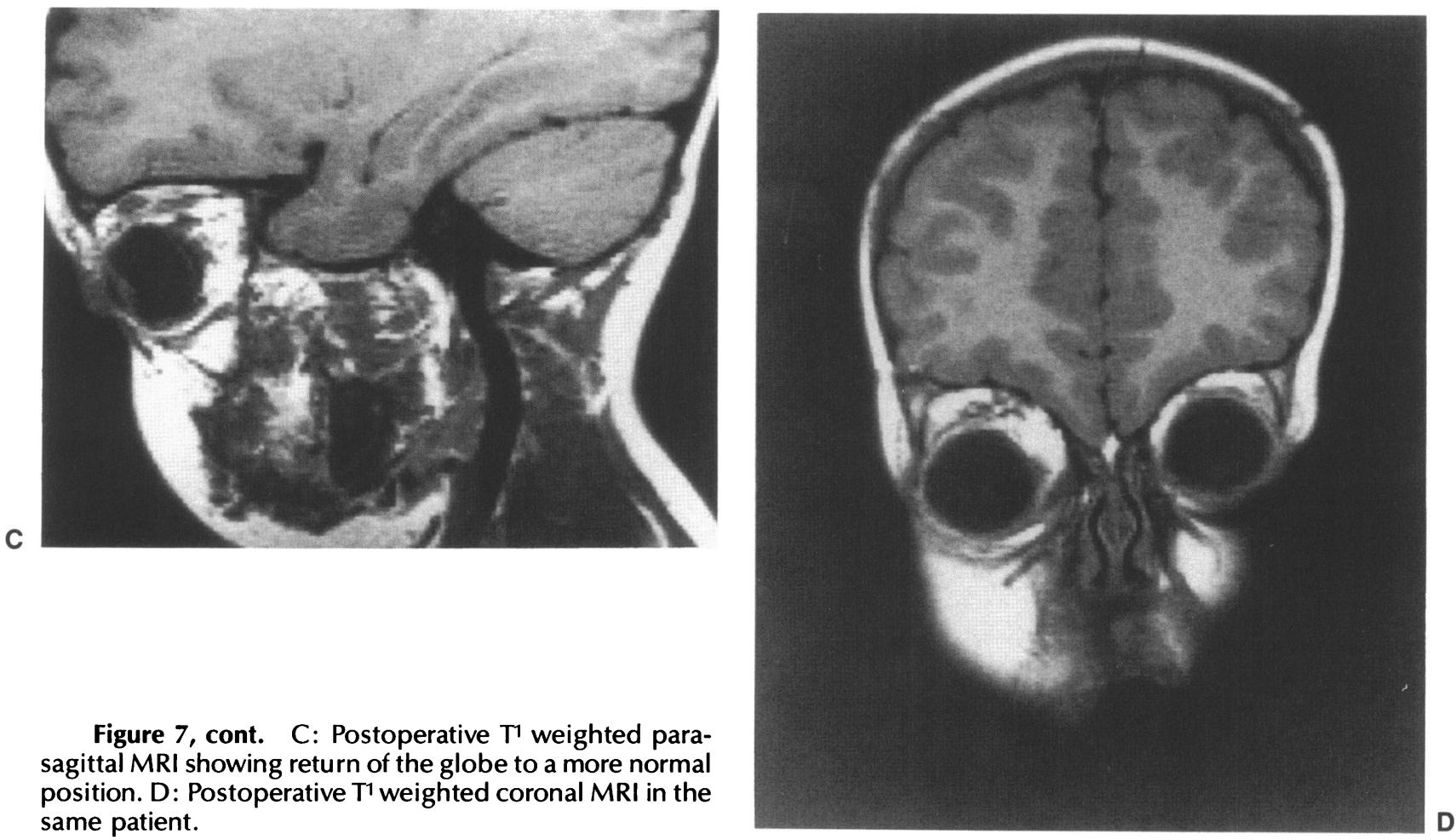

Figure 7 , cont. C: Postoperative $\mathrm{T}^{1}$ weighted parasagittal MRI showing return of the globe to a more normal position. D: Postoperative T1 weighted coronal MRI in the same patient.

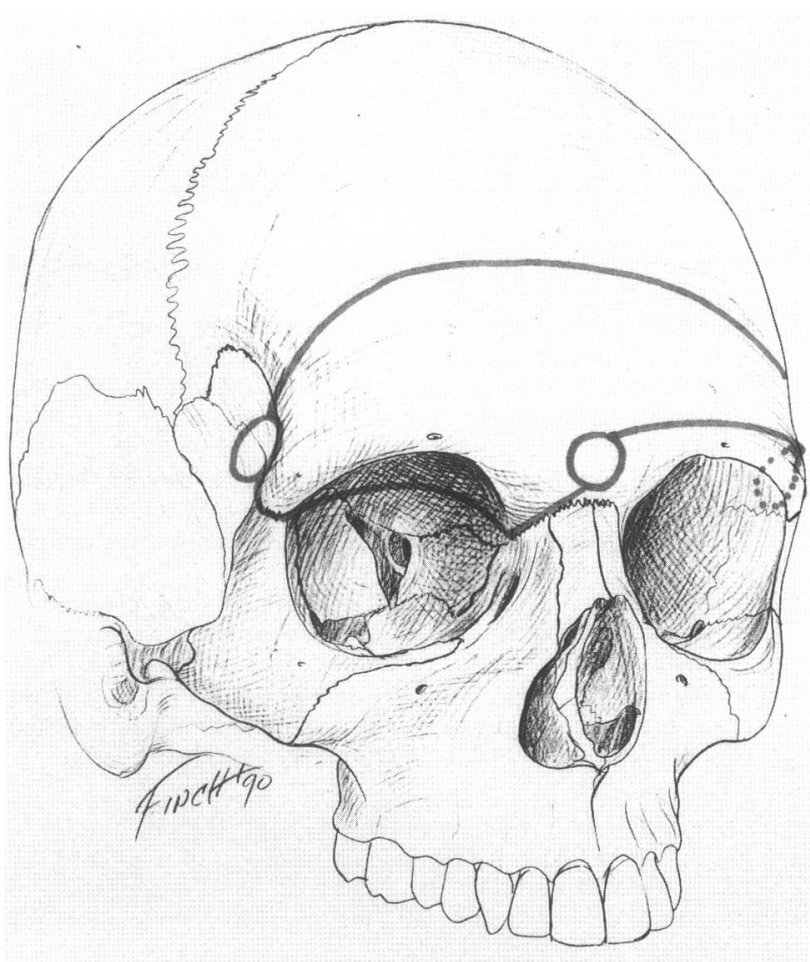

Figure 8. Artist's rendition of the bifronto-orbital craniotomy.

\section{Case 5}

This 9-year-old girl presented with uncorrected Crouzon's syndrome. Her mother likewise has uncorrected Crouzon's syndrome. Because the midfacial recession was relatively mild, the bifrontal-bizygomatic craniotomy was chosen for the procedure. The supraorbital bar was released by connecting the orbital osteotomies through the nasofrontal suture. The bilateral orbitozygomatic block was not actually removed but simply advanced and held in place with autologous bone grafts.

\section{DISCUSSION}

Craniofacial techniques have allowed significant advances in access to the orbit and anterior cranial fossa. Our purpose is to emphasize the flexibility of the approach and the importance of careful preoperative assessment of the extent of the lesion to be addressed, so that the extent of bony exposure can be tailored precisely to the lesion. The surgeon need not be reluctant to perform such extensive osteotomies because of concern for postoperative cosmetic deformity. Thin osteotomies using fine, high-speed bone dissecting instruments, reciprocating saws, or the Gigli saw often allow standard refixation techniques with 
A
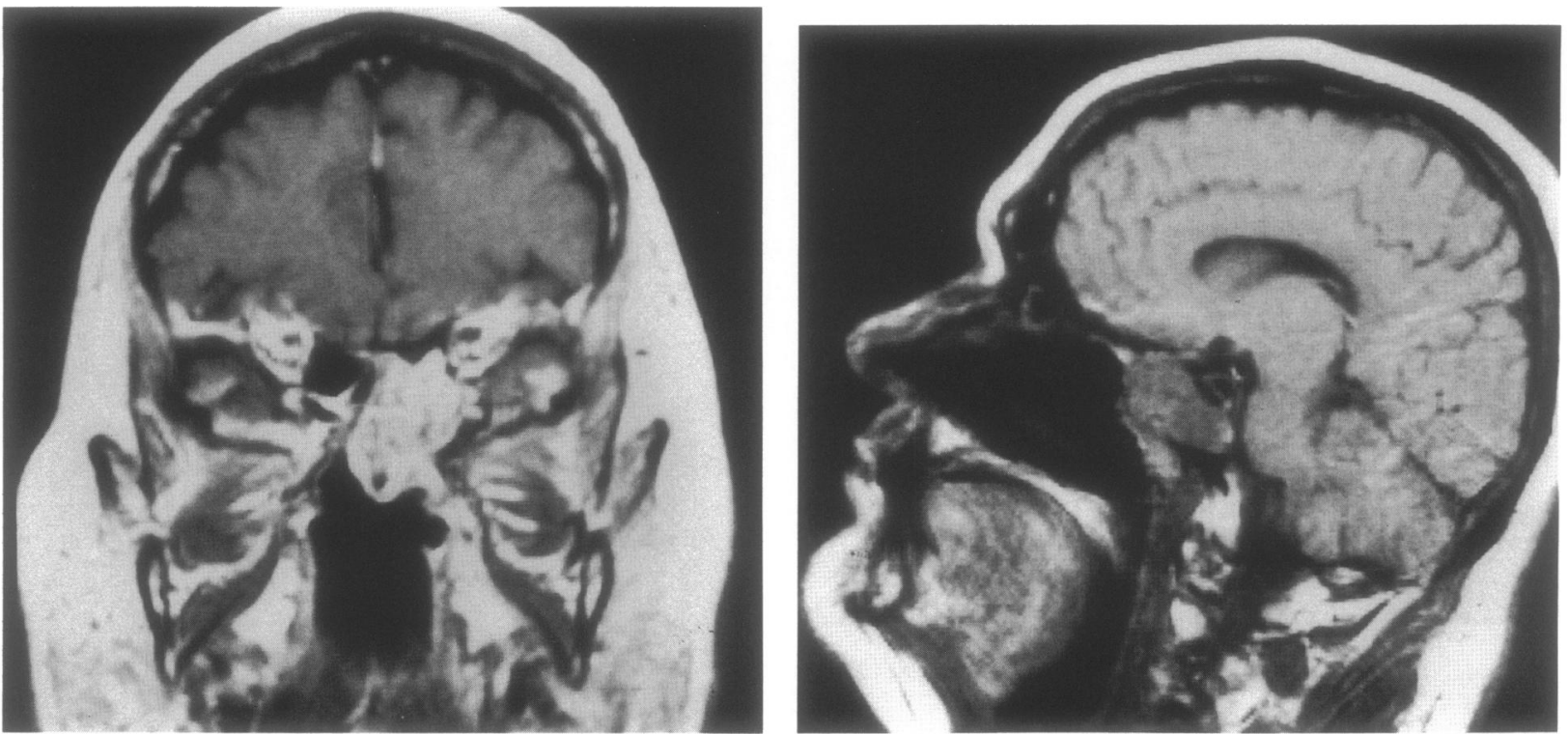

Figure 9. Coronal (A) and sagittal (B) $T 1$ weighted magnetic resonance imaging scans showing the recurrent squamous cell carcinoma reported in case 4 .

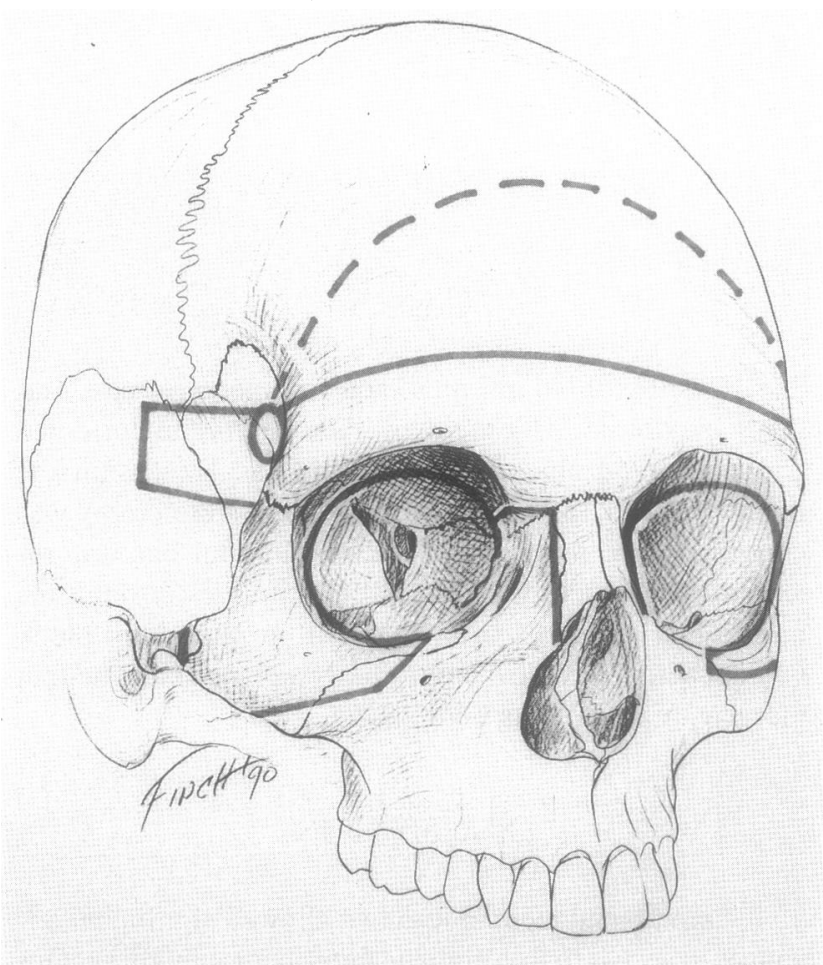

Figure 10. Artist's rendition of bifrontal bizygomatic craniotomy wire or suture to suffice. When larger bone defects are created, use of autogenous bone graft and rigid fixation techniques with miniplates can overcome the problems. These techniques are relatively straightforward when simple precautions are taken to protect the brain and eye and the outstanding exposure they afford should be within the armamentarium of every surgeon who addresses these lesions.

\section{REFERENCES}

1. Frazier $\mathrm{CH}$ : An approach to the hypophysis throughout the anterior cranial fossa. Ann Surg 57:145-152, 1913

2. McArthur LL: An aseptic surgical access to the pituitary body and its neighborhood. JAMA 58:2009-2022, 1912

3. Jane JA, Park TS, Pobereskin LH, Winn HR, Butler AB: The supraorbital approach: Technical note. Neurosurgery 11:537542,1982

4. Maroon JC, Kennerdell JS: Surgical approaches to the orbit. Indications and techniques. J Neurosurg 60:1226-1234, 1984

5. Al-Mefty O, Fox JL: Superolateral orbital exposure and reconstruction. Surg Neurol 23:609-613, 1985

6. Sekhar LN, Sen CN, Jho HD, Janecka IP: Surgical treatment of intracavernous neoplasms: A four year experience. Neurosurgery 24:18-30, 1989

7. McDermott MD, Durity FA, Rootman J, Woodhurst WB: Combined frontotemporal-orbitozygomatic approach for tumors of the sphenoid wing and orbit. Neurosurgery 26:107-116, 1990 


\section{REVIEWERS' COMMENTS}

The authors have presented a good review of the frontal orbital approaches to the anterior cranial base. These approaches have been discussed in detail in several textbook chapters. ${ }^{1-6}$ The orbital apex tumor presented in case 1 could also have been removed through a standard frontal temporal craniotomy with an extradural approach through the orbital roof. The authors have made an important point in emphasizing the flexibility of the approaches and correlation with preoperative evaluation of the radiographic studies in planning the operation.

Robert G. Ojemann, M.D.

Brooke Swearingen, M.D.

\section{REFERENCES}

1. Al-Mefty O: Surgery of the orbit. In Al-Mefty O (ed): Surgery of the Cranial Base. Boston: Kluwer Academic Publishers, 1989, pp 153-164

2. Anand VK, Al-Mefty O: Craniofacial lesions and resection. In Al-Mefty O (ed): Surgery of the Cranial Base. Boston: Kluwer Academic Publishers, 1989, pp 169-191

3. Jackson IT: Craniofacial osteotomies to facilitate the resection of tumors of the skull base. In Wilkins RH, Rengachary SS (eds): Neurosurgery Update I. New York: McGraw-Hill, 1990, pp 277-291

4. Newman SA, Jane JA: Meningiomas of the optic nerve, orbit and anterior visual pathways. In Al-Mefty $\mathrm{O}$ (ed): Maningiomas. New York: Raven Press, 1991, pp 461-494

5. Sekhar LN, Sen CN: An extended frontal approach to tumors involving the skull base. In Wilkins RH, Rengachary SS (eds): Neurosurgery Update I. New York: McGraw-Hill, 1990, pp 292-301

6. Sandaresan N, Sachdev V, Krol G: Craniofacial resection for anterior skull base tumors. In Schmidek HH, Sweet WH (eds): Operative Neurosurgical Techniques. Orlando: Grune \& Stratton, 1988, pp 609-618 